\title{
Inhalt der 17. Lieferung
}

Unlauterer Wettbewerb. Von Dr. Alexander Elster, Berlin (Schluß). . . . . 840

Unnatürlicher Tod s. Mord.

Unterschlagung s. Untreue und Unterschlagung.

Unterschrift. Von Dr. Hans Schneickert, Berlin . . . . . . . . . . 848

Untersuchung s. Voruntersuchung.

Untersuchungshaft. Von Staatsanwaltschaftsrat Dr. Karl Peters, Dozent an der

Universität Köln . . . . . . . . . . . . . . . . . . .

Untreue und Unterschlagung.

A. Kriminologie. Von Dr. Alexander Elster, Berlin? . . . . . . . . . .

B. Statistik. Von Regierungsrat Dr. Ernst Roesner, Berlin, Statistisches

Reichsamt . . . . . . . . . . . . .

Unzüchtige Schriften und Abbildungen s. Schmutz- und Schundschriften.

Urkundenfälschung.

A. Kriminelles. Von Dr. Hans Schneickert, Berlin . . . . . . . . .

B. Technisches. Von Dr. Georg Popp, Professor an der Universităt Frankfurt a. M. . . . . . . . . . . . . . . . . .

V.

Vagabunden s. Landstreicher und Bettler.

Verabredung des Verbrechens s. Komplott.

Verbrechen, statistisch s. Kriminalstatistik.

Verbrechensgenese. Von Dr. Ernst Heinrich Rosenfeld, Professor an der Universităt Münster i. W. . . . . . . . . . . . . . . . . .

Verbrechensursachen. Von Dr. Hans W. Gruhle, Professor an der Universität Bonn

Verbrechensverhütung. Von Oberverwaltungsgerichtsrat Dr. Max Hagemann, Berlin

Verbrecheralbum s. Erkennungsdienst.

Verbrecherhandschrift. Von Dr. Roda Wieser, Wien . . . . . . . . . . . 893

Verbrechertaktik. Von Dr. Hans v. Hentig, Professor an der Universităt Bonn . 894

Verbrechertum, organisiertes. Von Oberverwaltungsgerichtsrat Dr. Max Hagemann,

Berlin. . . . . . . . . . . . . . . . . . . 900

Verbrecherviertel. Von Oberverwaltungsgerichtsrat Dr. Max Hagemann, Berlin . 904

Verdunkelungsgefahr s. Kollusionsgefahr.

Vererbung. Von Dr. Hans W. Gruhle, Professor an der Universität Bonn . . . 904

Vergehen s. Kriminalstatistik.

Vergiftungen. Von Dr. Hermann Fühner, Professor an der Universität Bonn . 909

Verhaftung s. Untersuchungshaft, Festnahme, Verwahrung (polizeiliche).

Verkehrspolizei. Von Polizeimajor Gustav Langenscheidt, Berlin. . . . . . . 921

Verleumdung s. Lüge und Pathologisches Lügen.

VermiBte und unbekannte Tote. Von Kriminalkommissar Hans Bender, Berlin, Polizeiprăsidium ...................

Vermittlungsschwindel. Von Oberstaatsanwalt Dr. Krug, Berlin, Reichsjustizministerium .....................

Vernehmungstechnik. Von Hofrat Dr. Adolf Lenz, Professor an der Universităt Graz ....................... 933 